\title{
PROPHYLACTIC ANTICOAGULANT THERAPY IN PATIENTS WITH SPINAL CORD INJURY
}

\author{
By W. S. El MASRI, M.B., B.Ch., F.R.C.S.(Ed.) and \\ J. R. Silver, M.B., B.S., F.R.C.P.(Ed. \& Lond.) \\ National Spinal Injuries Centre, Stoke Mandeville, Aylesbury
}

Key words: Spinal injuries; Early anticoagulation.

THERE is a high risk of phlebothrombosis and subsequent pulmonary embolism in patients with traumatic spinal cord injuries. Walsh and Tribe (1965) reported their findings in 500 patients admitted to the National Spinal Injuries Centre (NSIC) within I4 days of injury. There were 66 cases of pulmonary embolus, I5 of which were fatal. The deaths occurred from 4-85 days following the onset of paraplegia. There were, however, no cases of pulmonary emboli among 123 patients who died after 3 months had elapsed since injury. As a consequence of these and similar findings, a regime of prophylactic anticoagulant therapy has been adopted at various spinal injury centres during the time that the patients are at risk (Silver \& Moulton, I970; Silver 1971; Silver 1974; Hachen 1974; Watson 1978). However, it has still not been defined how long this should be administered and what regime is the most effective.

The purpose of this paper is to present the results of management with anticoagulant therapy in a series of $\mathrm{IO2}$ consecutive patients with traumatic paraplegia and tetraplegia treated at this Centre between May I976 and July I979 and to assess the factors that influence the occurrence of this complication and the optimum duration of treatment.

\section{Clinical Material}

\section{Materials and Methods}

The study concerns I02 consecutive male traumatic spinal cord injury patients admitted to one ward at the NSIC between May I976 and July I979.

There were 54 cervical, 36 thoracic and 12 lumbar lesions. There were 59 road traffic accidents, 17 sporting injuries and 26 others. Fifty had major associated injuries. Eighteen patients were admitted within 2 days of injury, I 3 patients between day 2 and day 7,22 patients between day 8 and day I4, and 49 patients were admitted 15 or more days after injury.

\section{Regime and Treatment}

No patients were directly admitted; all were transferred from a receiving hospital. The regime and management of the patient and of the anticoagulant therapy and the criteria for the diagnosis of pulmonary embolus are given in the paper by Silver, I974.

Sixty-six patients were anticoagulated. In 36 patients anticoagulation therapy was not administered. Twenty-four of them were admitted more than 12 weeks after injury when the risk of pulmonary embolism was thought to have passed. 
Seven patients had such severe associated injuries that the risk of anticoagulation was thought to outweigh the advantages. Two patients had a history of an active duodenal ulcer. One had a ruptured jejunum, one was hypertensive and one had disturbed liver function tests.

\section{Complications}

The only complication that necessitated discontinuation of the treatment was bleeding. This contributed to the death of a 73-year-old patient.

\section{Results}

I. Nineteen patients developed pulmonary emboli. One patient had at least three separate episodes. (C.C.). None of these patients were effectively anticoagulated, in that the prothrombin ratio was either below the recommended range of $I \cdot 8$ to $2 \cdot 5$ or that the prothrombin ratio was within the range but the anticoagulation period was less than a week or they did not receive therapy at all.

2. Six of these ig patients had already had pulmonary emboli prior to admission to the Centre. Only one of these was on anticoagulant therapy at the time. His embolus occurred 6 days after injury, before he had been under effective control for a week.

3. Eight patients who were admitted between 3 and 70 days after injury had pulmonary emboli soon after admission before they were effectively anticoagulated. (Table I.)

4. Four patients had pulmonary emboli after the anticoagulants had been discontinued. One because of septicaemia, another because of a flare-up of a duodenal ulcer. One high risk case who had had two previous pulmonary emboli had his anticoagulant therapy discontinued for elective surgery on his bladder. A further patient had his arbitrarily discontinued when he got up, although he had a deep vein thrombosis. (Table II.)

5. Only eight of the I 9 patients who had a pulmonary emboli had clinically detectable deep vein thrombosis. In seven of these it was found prior to the pulmonary embolus and in one it was found simultaneously.

6. Three patients in the whole series died. In two of these the cause of death was attributed to bronchopneumonia, and one had a carcinoma of the stomach in addition. Their ages were 64 and 73. The third patient, aged 73, died from bleeding from a peptic ulcer. A carcinoma of the left pelvi-ureteric junction was also present, and a pulmonary embolus, which was not considered to be the cause of death, was found at postmortem.

7. Only one patient who had an embolus at the Centre had such severe associated injuries (a severe head injury) that he could not be anticoagulated, as the risk of further bleeding was considered too high.

8. The only group of patients who did not suffer from a pulmonary embolus was a small group of five patients who started anticoagulant therapy within two days of injury. 


\section{Discussion}

This demonstrates the effectiveness of early and adequate treatment with oral phenindione in preventing clinically significant pulmonary embolus in acute paraplegia. No patient who was known to be properly anticoagulated developed symptoms of an embolus. Emboli only occurred during the first week of therapy, when dosage was inadequate, or after it had been stopped. Possible exceptions were two patients who developed pulmonary emboli at other hospitals for whom we do not know the dates of therapy or how well it was controlled.

Compared with the last report from this Centre (Silver, 1974) the incidence of pulmonary embolus was high. In this study there were 2I episodes of embolus in I02 patients. In the previous report seven episodes occurred in IOO patients. The composition, aetiologies and incidence of associated injuries were similar and nursing and medical regimes were the same. An obvious difference was the delay in admission. In the present series 18 patients were admitted within 2 days of injury and a total of 3I patients within 7 days of injury, whereas in the 1974 study 42 patients were admitted within 2 days and 59 within 7 days. Anticoagulant therapy was consequently instituted later on average in the present series. It was unfortunate that lack of staff and facilities at this Centre prevented early admission, while clinicians at the receiving hospitals evidently did not appreciate the need for early anticoagulant therapy. It is noteworthy that I4 patients had their emboli either before or soon after admission and before they could be effectively anticoagulated, whereas no emboli were observed in the five patients in whom phenindione therapy was started by the second day following injury.

Pulmonary embolus arises as a result of the detachment of thrombi from the veins in the pelvis and the lower limbs. To be effective, treatment must commence before these become thrombosed and continue after the risk period has passed. Once the deep veins are thrombosed, anticoagulants cannot prevent pulmonary emboli occurring (Hunter, Sneeden et al., I94I; Hunter, Kryger et al., 1945).

The deep veins of the legs become thrombosed within a week in 15 per cent of patients confined to bed (Gibbs, 1957) and in 50 per cent of patients following major trauma (Sevitt \& Gallagher, I959 \& I96I). In paraplegics, Todd, Frisbie et al. (1976) found Ioo per cent incidence in 14 patients by 60 days after injury. When started, oral anticoagulants are not immediately effective. These drugs act by reducing the synthesis of various clotting factors, factor 7 initially, and eventually factors 5,9 and Io. The reduction of factor 7 at an early stage does not ensure effective anticoagulation and it may take a week for factors 5, 9 and io to be sufficiently reduced. Prophylactic anticoagulation therapy must therefore be commenced at the earliest possible moment after injury.

Therapy was normally discontinued at 3 months, since by this time the risk period was thought to have passed. Two patients, however, had pulmonary emboli following cessation of therapy at or after this time. Two others had emboli following cessation of therapy at earlier dates (Table II) in spite of the fact that the dosage of anticoagulant was reduced gradually to avoid the possibility of a rebound phenomenon. Perkash (1978) has also reported the occurrence of pulmonary emboli 3 months or more after injury, and in the previous series (Silver, 1974) there were three episodes of deep vein thrombosis and one of pulmonary embolus following termination of therapy. There is therefore a need for prophylactic anticoagulant therapy to be continued for a longer period in high risk patients (those with obesity or previous deep vein thrombosis or pulmonary embolus). It is now our practice to continue if possible for up to 6 months in such cases. 


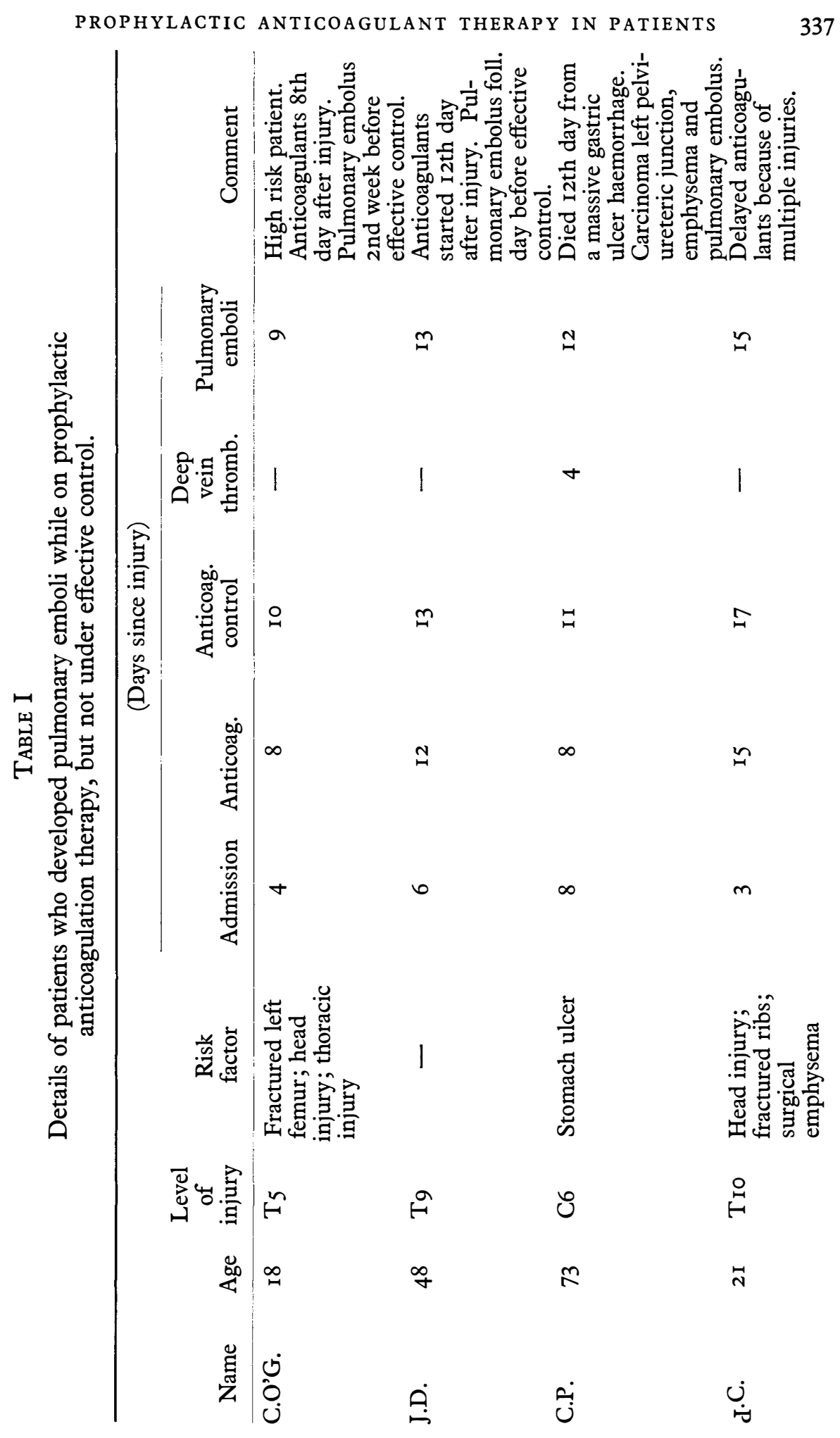




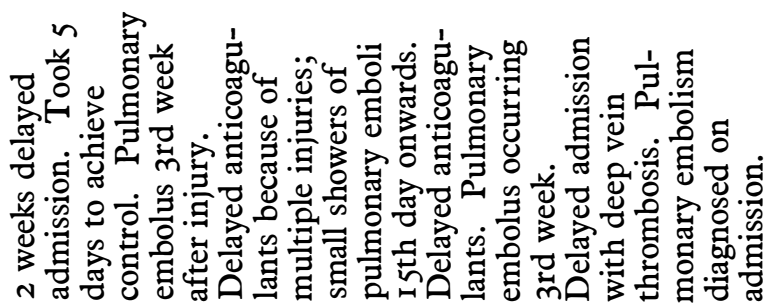

ㅇำ

$\approx$

2

온

รับ

I

l

웅

ㅇำ

4

ำ

A

$\mathfrak{n}$

$\stackrel{\sim}{N}$

9

용

$m$

$\mathbb{Z}$

$m$

온

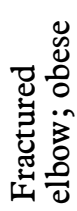

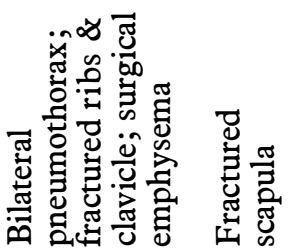

$\stackrel{2}{H}$

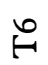

H

ลิ

$\stackrel{\infty}{\oplus}$

$\stackrel{\infty}{m}$

i

近

$\stackrel{4}{\Sigma}$

留

$\sum_{j}^{\dot{j}}$

$\mathfrak{u}$ 


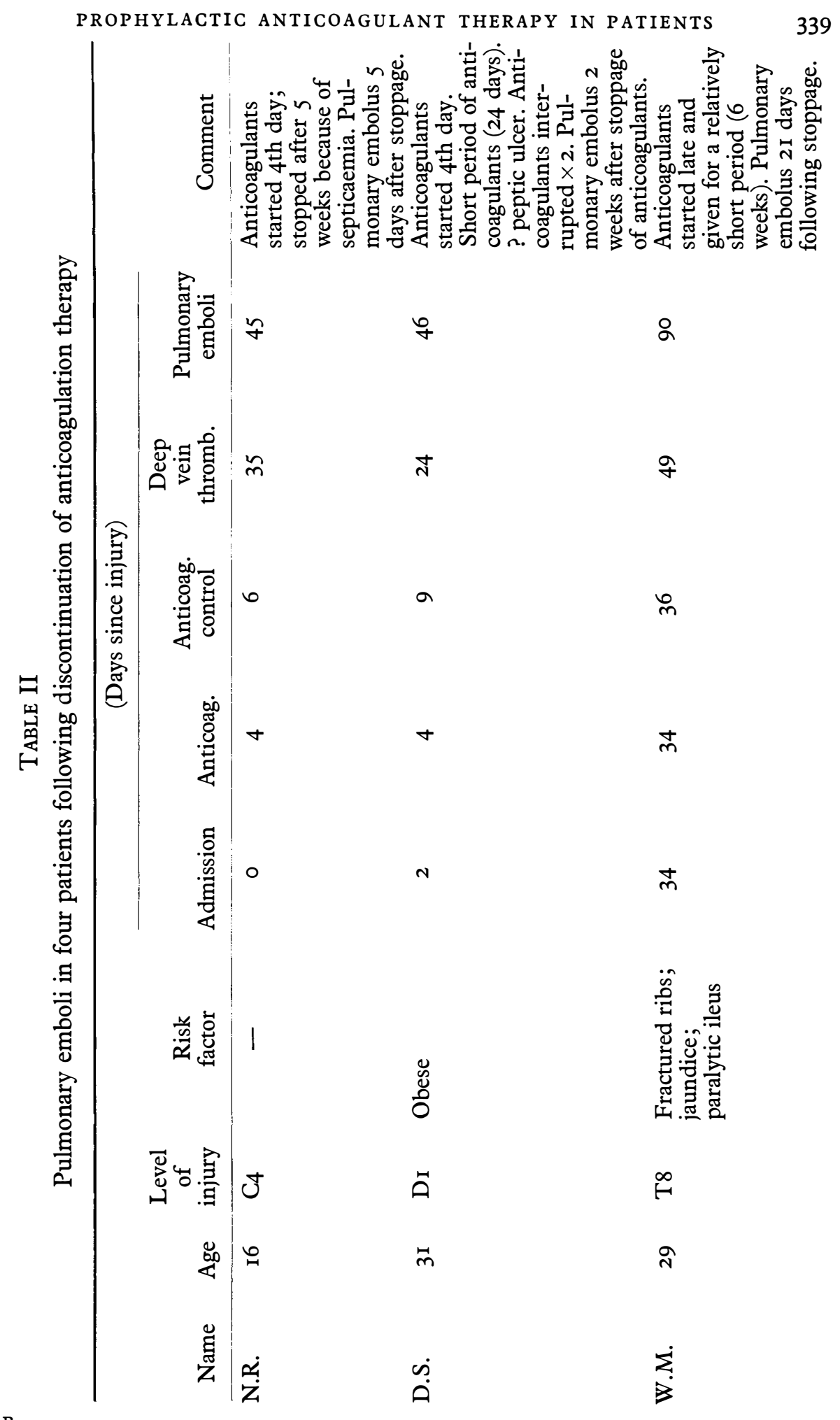




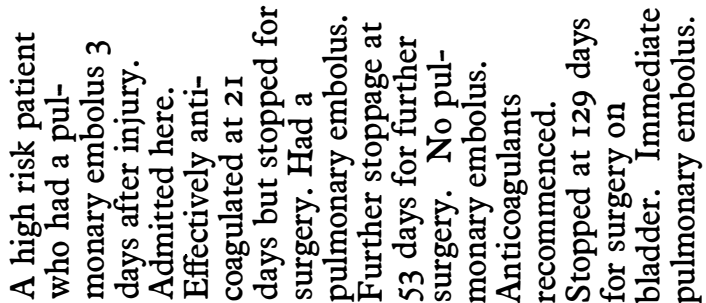

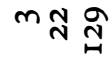

$\hat{-1}$

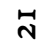

$\stackrel{\infty}{\sim}$

N

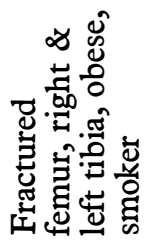

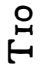

พ

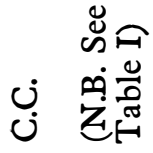


A disadvantage of full anticoagulation is that regular blood sampling for determination of prothrombin index is necessary. Others have used low dose heparin therapy (Hachen, 1974; Watson, 1978). Kakkar (1972), however, reported failure of low dosage heparin in the prophylaxis of deep vein thrombosis in patients with fractured necks of femur. Watson (I980) and Jones (I980) have reported deaths from pulmonary emboli while using this prophylactic regime in paraplegics.

In the experience of one of the authors (Silver and Moulton, I970; Silver, I974; this report) at least 250 patients have been treated by full anticoagulation, and there has not been one death from pulmonary embolus, nor has the drug caused any ascent of the spinal cord lesion although haemorrhage may have contributed to death in one elderly patient.

\section{Conclusions}

I. Unless specifically contra-indicated, therapy with oral anticoagulant drugs should be instituted within 48 hours of injury and continued for at least 3 months.

2. The regime of prophylactic anticoagulation should be extended up to 6 months in those patients with added established risk factors.

\section{SUMMARY}

One hundred and two consecutive acute traumatic spinal injury patients admitted between 1976 and 1979 to a male ward at Stoke Mandeville Hospital were considered for prophylactic anticoagulant therapy. Sixty-six were anticoagulated. Thirty-six were not due to various contra-indications. Nineteen patients had pulmonary emboli. None of these were effectively anticoagulated. These results are compared with a similar previous series where there was a smaller incidence of emboli. The main reason for this was due to the delay in admitting patients to the Centre so that they could not be anticoagulated early enough to prevent pulmonary embolus occurring. In those patients who had a pulmonary embolus or were considered to be a high risk, anticoagulant therapy was continued for 6 months.

\section{RÉSUMÉ}

Durant la période entre I976 et I979, IO2 malades avec des injures de la moelle épinière étaient consécutivement admis dans une salle pour mâles. 66 malades furent anticoagulés prophylatiquement. 36 malades n'ont pas reçu d'anticoagulant dû a des contraindications variées. I9 malades ont subi un embole pulmonaire; aucun n'était effectueusement anticoagules.

Ce resultat comparé à une serie similaire où l'incident d'embole pulmonaire était moins nombreux.

L'on attribue cette différence au délai de l'admission de ces malades au centre et consecutivement au délai de l'anticoagulation.

Les malades qui ont subi une embole pulmonaire et ceux qui présentent un grand risqué étaint anticoagulés pour une période de 6 mois.

\section{ZUSAMMENFASSUNG}

Bei 102 Patienten, die zw1schen 1976 und 1979 mit akuter posttraumatischer Querschnittslähmung eingeliefert wurden, wurde eine prophylaktische Antikoagulantien Therapie erwogen; 66 wurden antikoaguliert, 36 nicht wegen verschiedener Kontraindikationen. I9 Patienten bekamen eine Lungenenbolie. Keiner von diesen war ausreichend antikoaguliert worden. 
Diese Ergebnisse werden mit einer ähnlichen Untersuchungreihe mit geringerem Embolievorkommen verglichen. Der Unterschied ist vorallem durch die Verzögerung der Einweisungen ins Zentrum zu erklären. Die Patienten konnten daher nicht frühzeitig genug antikoaguliert werden, um die Entstehung von Lungenemboli zu verhindern. Bei Patienten, die eine Lungenembolie durchgemacht hatten, oder bei solchen mit hohem Risikofaktor wurde die Therapie sechs Monate lang durchgeführt.

Acknowledgements. We would like to thank Dr C. S. Pitcher, Consultant Haematologist for his kind co-operation and advice and Dr R. G. Burr for his critical suggestions and help with the manuscript.

\section{REFERENCES}

GiBBs, N. M. (1957). Venous thrombosis of the lower limbs with particular reference to bedrest. The B.F.S., XLV, I9I, 209.

HACHEN, H. J. (I974). Anticoagulation therapy in patients with spinal cord injury. Paraplegia, I2, I76-I 87.

Hunter, W. L., Kryger, J. J., Kennedy, J. C. \& Sneeden, V. D. (1945). Aetiology and prevention of thrombosis of the deep left vein. Surgery, $\mathbf{1 7}, \mathbf{1 7} 8$.

Hunter, W. L., Sneeden, V. D., Robertson, T. D., \& SNYder, G. A. L. (I94I). Arch. Internal Medicine, 68, I.

JONES, H. W. F. (I980). Personal communication.

KAKRAR, V. V., CORRIGAN, T. \& SPINDLER, J. et al. (I972). Efficacy of low doses of heparin in prevention of deep vein thrombosis after major surgery. Lancet, ii, IOI.

Perkash, I. (1978). Experience with the management of thrombo-embolism with spinal cord injuries. Part I. Incidence, diagnosis and role of some risk factors. Paraplegia, 16, 322-33I.

Seviti, T. \& Gallagher, N. G. (1959). Prevention of venous thrombosis and pulmonary embolism in injured patients. Lancet, $\mathbf{i}, 98 \mathrm{I}$.

SevitT, S. \& Gallagher, N. G. (I96I). Venous thrombosis and pulmonary embolisma clinicopathological study in injured and burned patients. B.F.S., 48, 475 .

SILVER, J. R. \& MOULTON, A. (I970). Prophylactic anticoagulant therapy against pulmonary emboli in acute paraplegia. B.M.F., 2, 338-340.

SILVER, J. R. (I97I). Prophylactic anticoagulant therapy in the prevention of pulmonary emboli in patients with acute spinal cord injuries. Proceedings of 18 th Veterans Symposium, Boston, 184. Ann. R. Coll. Surg. Engl., I7.

SILVER, J. R. (I974). The prophylactic use of anti-coagulants in the prevention of pulmonary emboli in 100 consecutive spinal injury patients. Paraplegia, 12, I88-196.

Todd, J. S., Frisbie, J. H., Rossier, A. B., Adams, D. F., Armenia, A. V., Sassahaka, A. A. \& Tow, D. E. (I976). Deep vein thrombosis in acute spinal cord injury: a comparison of 125 fibrinogen leg scanning, impedance plethysmography and venography. Paraplegia, 14, 50-57.

Walsh, J. J. \& TRIBE, L. R. (1965). Phlebothrombosis and pulmonary embolism in Paraplegia. Paraplegia, 3, 209-213.

Watson, N. (1978). Anticoagulant therapy in the prevention of venous thrombosis and pulmonary embolism in the spinal cord injury. Paraplegia, 16, 265.

Watson, N. (I980). Personal communication. 